\title{
Role of Adsorbents in Treatment of Pollutants from Aqueous Medium (A-Review)
}

\author{
ESMAT LAIQ ${ }^{1}$, SHAGUFTA JABIN and PRITI GUPTA ${ }^{3}$ \\ ${ }^{1}$ Chemistry Section, Women's College, Department of chemistry, Aligarh Muslim University, \\ Aligarh-202 002 (UP), India. \\ 2Department of Chemistry, Faculty of Engineering \& Technology, Manav Rachna International Institute \\ of Research and Studies, Sector-43, Suraj kund Road, Faridabad-121 001, Haryana, India. \\ ${ }^{3}$ Department of Chemistry, Manav Rachna University, Faridabad, India. \\ *Corresponding author E-mail: shaguftaajabin@gmail.com \\ http://dx.doi.org/10.13005/ojc/370414
}

(Received: June 07, 2021; Accepted: July 16, 2021)

\begin{abstract}
This paper will provide an outline of the dissolved pollutants and their removal techniques from water and wastewater. Dissolved impurities are omnipresent in all kinds of water like ground water, surface water and other industrial sewage. Many methods are available for the treatment of dissolved pollutants. Rather than the conventional methods such as membrane technology, coagulation-flocculation method, electro dialysis, and ion exchange method for removing dissolved impurities from a different kind of water, the applicability of the adsorption technique is a simple, economical and the most potential one. Adsorbents may be conventional and non-conventional. Activated carbon and silica gel are included in conventional materials. Activated carbon is preferred material for removing pharmaceutical waste, heavy metals, and dyes from an aqueous medium. They can remove larger and smaller particles from water and wastewater due to their porosity. Among non-conventional methods, clay minerals and zeolites are used in both natural and modified forms as potential adsorbents. Bio-sorbents like industrial waste, agro waste, and chitosan have unique properties to be used as adsorbents to remove dissolved impurities from an aqueous medium. It also outlines mechanism of adsorption and complex relation between adsorbents and adsorbates. Considering the applicability of different adsorbents discussed here for the removal of heavy metals, pharmaceutical waste, dyes, and organic waste, it is expected that this technique can be helpful in further treatment in variety of water and wastewater.
\end{abstract}

Keywords: Bio-sorbents, Conventional, Non-conventional, Adsorbents, Membrane technology.

\section{INTRODUCTION}

Over the last few decades, water quality is declining mainly due to overpopulation, anthropogenic activities, rapid industrialization, and unplanned urbanization. To minimize disturbance of the ecological balance of the receiving water, it should be treated before getting discharged to the environment. The pace with which countries are growing is genuinely frightening because the

This is an Open Access article licensed under a Creative Commons license: Attribution 4.0 International (CC- BY). Published by Oriental Scientific Publishing Company @ 2018 
human population with its associated sanitation problems will grow faster than the increase in the amount of accessible quality water. Groundwater and Surface water are two significant sources of water. Generally, surface water is present in the lake, rivers, and other freshwater wetlands. However, groundwater is present in the pores of rocks and soil and flowing below the water table. Impurities are generally present in both kinds of water ${ }^{1,2}$. In addition, the awareness of the importance of clean water has pushed the environmentalists towards the development of sustainable, environmentally friendly, and economic processes capable of minimizing impurities from water and wastewater and, simultaneously, safeguarding the health of living organisms ${ }^{3,4}$. Despite the great effort, human being in present era continues to face challenges for water pollution. The whole range of water impurities is divided into two different categories:

(i) Suspended matters

(ii) Dissolved matters

Suspended matters are further classified into Settleable suspended matter and non Settleable suspended matter. The size range of different kinds of matters is as follows:

(i) Dissolved matters: 0 to $0.08 \mu \mathrm{m}$

(ii) Non-settleable suspended matters: 0.08 to $100 \mu \mathrm{m}$

(iii) Settleable suspended matters $>100 \mu \mathrm{m}$

The findings of different environmentalists were summarized by Munch et al., in 1980, and he classified the contaminants according to their size ${ }^{5}$. According to him, BOD, COD, turbidity, and TSS are mainly present in suspended form ${ }^{5}$. However, phosphorus, pathogens, hardness, radioactive substances, organic matter, heavy metals, dyes, and pharmaceutical waste are mainly present in dissolved form ${ }^{6,7}$. The manuscript will cover the emphasis on the removal of dissolved impurities from water and wastewater. Therefore, the need of the hour is to have an efficient technique for the removal of all dissolved impurities from various water bodies like groundwater, surface water, and industrial wastewater ${ }^{8,9}$.

\section{Sustainable Desalination Methods for Removal of Dissolved Pollutants}

Different kind of treatment techniques is available with various degree of success to minimize and control water pollution. There are many methods available for the removal of dissolved impurities from water and wastewater. The different techniques available are the ion-exchange method, precipitation method/coagulation-flocculation method, chemical oxidation method, membrane filtration method, and adsorption method ${ }^{10,11}$. The ion exchange method removes the impure ions from water by exchanging ions ${ }^{12}$. However, the ion exchange method has its own limitations. The precipitation/coagulationflocculation method is used in water treatment to remove impurities like suspended solids and heavy metals from water ${ }^{3}$. However, it is a more efficient technique for removing suspended particles from a different kind of water. Nevertheless, critical drawbacks involve in the coagulation-flocculation process are a high level of water mineralization, low efficiency, and a large amount of sludge generation ${ }^{13}$.

The use of membranes for water treatment has been used in recent decades. However, all drinking water contaminants cannot be removed by the membrane process alone. There are different types of membranes available for water treatment, viz. Ultra-filtration(UF), nano-filtration(NF), and reverse osmosis. However, the running cost of membrane filtration is very high. Reverse osmosis is generally used to remove salts from saline water ${ }^{14}$. It is an efficient technique for domestic purposes, but it cannot be used on a large scale to remove dissolved impurities. The electrodialysis technique is also used to remove dissolved impurities and softens saline water $^{6}$. The installation cost of the electrodialysis method is very high.

Chemical oxidation processes are also used to treat drinking water ${ }^{15}$. Chemical oxidants are generally used for the removal of hazardous organic compounds and inorganic contaminants. However, this process is generally used before the coagulation-flocculation method ${ }^{16}$. Because the oxidation process alone is not sufficient to get the best results, it is generally combined with the coagulation-flocculation method. However, the limitations of most of these methods are generation of a large quantity of sludge, high operating cost, maintenance cost, and complex steps involved in the treatment process. From an environmental point of view, the adsorption method is the most sustainable technique for removing dissolved impurities 
from different water bodies like surface water, groundwater, and even industrial wastewater. The advantages and limitations of different desalination techniques have been shown in Table 1.

Table 1: Advantages and limitations of different desalination techniques

\begin{tabular}{|c|c|c|}
\hline Techniques & Advantages & Limitations \\
\hline $\begin{array}{l}\text { Precipitation/Coagulation- } \\
\text { flocculation Method }\end{array}$ & $\begin{array}{l}\text { Efficient; commercially } \\
\text { available chemicals }\end{array}$ & $\begin{array}{l}\text { Adjustment of } \mathrm{pH} \text { is required; formation of high } \\
\text { amount of sludge in treated water }\end{array}$ \\
\hline $\begin{array}{l}\text { Reverse osmosis method/ } \\
\text { Membrane Technology }\end{array}$ & Efficient Method & $\begin{array}{l}\text { High capital cost and high running cost; production } \\
\text { of Toxic wastewater. }\end{array}$ \\
\hline Ion-exchange Method & Efficient Method & $\begin{array}{l}\text { Vulnerable to interfering ions like phosphate, } \\
\text { chloride, sulphate and bicarbonate, Costly; } \mathrm{pH} \\
\text { dependent; Regeneration leads to toxic liquid waste }\end{array}$ \\
\hline Electrodialysis Method & Efficient Method & High cost of installation and maintenance. \\
\hline Oxidation Method & $\begin{array}{l}\text { Used successfully for degradation } \\
\text { of organic contaminants. }\end{array}$ & high capital, operating and maintenance cost \\
\hline Adsorptive materials & $\begin{array}{l}\text { Highly efficient, Low cost, Availability } \\
\text { of large variety of adsorbents, Simple operation }\end{array}$ & Sometime $\mathrm{pH}$ adjustment required \\
\hline
\end{tabular}

\section{Mechanism of Adsorption Method}

Adsorption is a surface phenomenon for the removal of salts from a different kind of water. When dissolved salts come in contact with solid adsorbents, it results in solid-liquid interaction due to the electrostatic force of attraction. This electrostatic force of attraction can be physisorption or chemisorption in nature. In physisorption, adsorbent and adsorbate combine by Van Der Waal forces, and the process is reversible ${ }^{19,20}$. However, in the case of chemisorption, adsorbate, and adsorbent combine by a covalent bond. Contrary to physisorption, chemisorption exists as a single layer. In chemisorption, substances adsorbed on solid surfaces are difficult to remove because of stronger bonds ${ }^{21}$. Both chemisorption and physisorption can coincide in favourable conditions. Physical adsorption is carried out by lowering entropy and free energy from the adsorption system, and thereby this process is exothermic ${ }^{22}$. As the process of adsorption progress, equilibrium exists between adsorbate and adsorbent. The following equation can be used to evaluate adsorption efficiency:

$$
\mathrm{Qe}=\mathrm{V}(\mathrm{Co}-\mathrm{Ce}) / \mathrm{M}
$$

Here $\mathrm{V}$ denotes the volume of the solution. $\mathrm{M}$ is the volume of adsorbent. Co and $\mathrm{Ce}$ are initial and equilibrium adsorbate, respectively. Qe is the adsorption amount of the molecule ${ }^{22}$. The mechanism of physisorption and chemisorption has been shown in Figure 1.

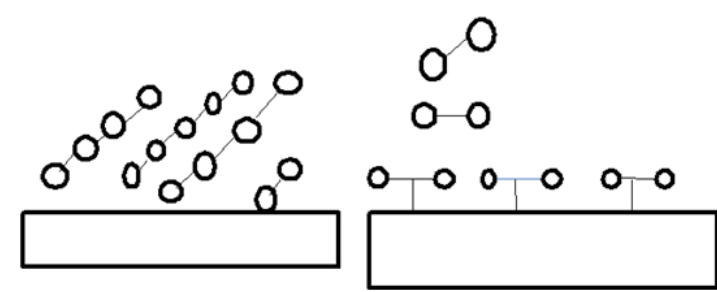

Fig. 1. Mechanism of Physisorption \& Chemisorption Role of Different Adsorbents in Desalination

The selection of proper adsorbent types for removing contaminants from an aqueous medium is generally an important task. Many adsorbents are available with various physical and chemical properties ${ }^{23}$. Adsorbents are generally classified into conventional and non-conventional adsorbents. Furthermore, conventional adsorbents include activated carbon and silica gel, and non-conventional adsorbents include natural adsorbents and biosorbents ${ }^{24}$. The complete classification of adsorbents has been shown in Fig. 2. The natural materials are abundant in supply, cheap, and having great potential to be used as adsorbents in different kinds of water ${ }^{25}$.

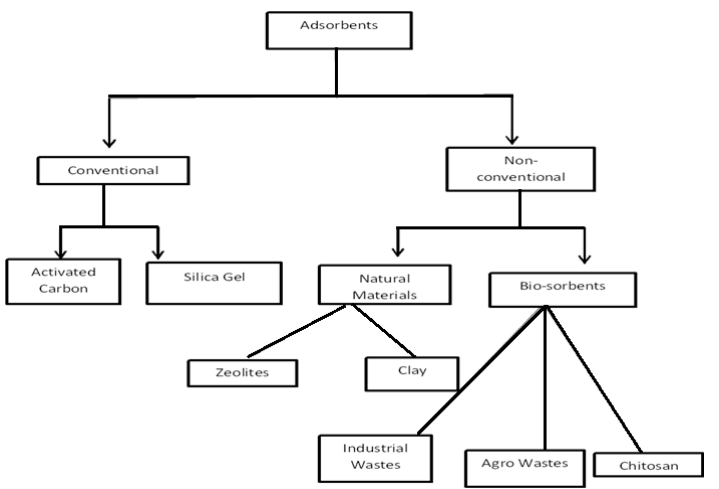

Fig. 2. Different types of adsorbents 


\section{Conventional adsorbents Activated carbon}

It is one of the most significant adsorbents for removing various salts from ground and surface water ${ }^{26}$. It can cope with a wide range of dissolved impurities. Activated carbon is formed from different raw materials. That is why it has vast properties also ${ }^{27}$. Characteristics of coal also depend upon the activation process, which carries out at a temperature range of $800^{\circ} \mathrm{C}$ to $1000^{\circ} \mathrm{C}$. The properties of activated carbon also depend upon its bulk density.

As per porosity, it is characterized into three categories viz. macroporous, microporous and mesoporous carbon ${ }^{28}$. Macroporous carbon and microporous carbon have a bulk density of $>1$ $\mathrm{cm}^{3} / \mathrm{g}$ and $<0.85 \mathrm{~cm}^{3} / \mathrm{g}$, respectively. However, the bulk density of mesoporous carbon is in the range of 0.85 to $1.0 \mathrm{~cm}^{3} / \mathrm{g}$. As per literature, mesoporous carbons and macroporous carbon are generally used more efficiently for the adsorption of larger particles, particularly liquid pollutants ${ }^{29}$. However, microporous is generally used for the removal of small size contaminants. The size of macroporous, mesoporous and microporous are $>50 \mathrm{~nm},<50 \mathrm{~nm}$, and $<2 \mathrm{~nm}$, respectively ${ }^{29}$. Activated carbon has remarkably developed internal surface area. A schematic model of activated carbon has been shown in Figure 3.

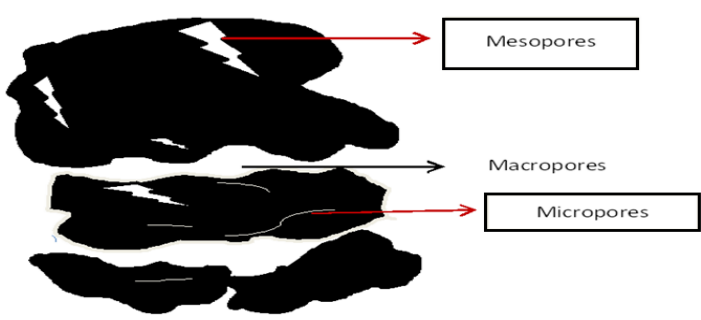

Fig. 3. Schematic model of activated carbon ${ }^{30}$

Activated carbon is mainly made up of a graphite layer with a porous structure ${ }^{30}$. Carbonaceous matrix also has carbon, nitrogen, oxygen, hydrogen, phosphorus, and Sulphur. Few acidic groups such as carboxylic acid, carboxylic anhydride, hydroxyl, and carbonyl are present on its surface. In addition, some basic groups like pyrenes and chromenes were also identified. Adsorption on the surface of activated carbon takes place by physical and chemical adsorption methods. In physical adsorption, there is no exchange of electrons between adsorbate and adsorbent ${ }^{29}$. However, in chemical adsorption, there is sharing or transfer of electrons between adsorbate and adsorbent. Temperature and ionic strength are also important parameters for measuring the efficiency of activated carbon in the adsorption process ${ }^{31}$. Surface area, pore-volume, and diameter of macroporous, mesoporous, and microporous have been summarized in Table 2 .

Table 2: Characteristics of different categories of activated carbon

\begin{tabular}{lccc} 
Categories & Diameter $(\mathrm{nm})$ & Surface area $\left(\mathrm{m}^{2} / \mathrm{gm}\right)$ & Pore volume \\
\hline Macropores & $>50.0$ & $0.5-2$ & $0.20-0.80$ \\
Mesopores & $2-50$ & $20-70$ & 0.02 \\
Micropores & $<2.0$ & $600-1900$ & 0.10 \\
\hline
\end{tabular}

\section{Silica gel}

A large class of silica contains silica powder, silica gels, aerogels, pyrogenic silica, mesoporous silicas, and aluminosilicates silica nanoparticles with different sizes of pores ${ }^{32}$. Pure silica gel is usually extracted by the sol-gel process in aqueous solutions. It is extracted by condensation of the siloxane bonds and hydrolysis of silane, resulting in anhydrous $\mathrm{SiO}_{2}$ in monolithic or powdered form. However, silica aerogels have a porous structure produced by drying the silica gels under favourable conditions. It consists of an irregular tridimensional framework of alternating semiconducting material and chemical element atoms with minimal voids and pores. The voids generally contain water or some other liquids ${ }^{33}$.

The silica gel surface permits the sorption of metals ions and pharmaceutical waste very efficiently ${ }^{34}$. Silica gel could also be doped with a wet indicator that delicately changes its color once it transitions from the anhydrous dry state to the hydrous wet state. Silica gel is non-flammable, non-toxic, non-reactive, and stable. Silica gels are generally having low bulk density and high porosity. Among all kinds of silica, mesoporous silica gel is the most versatile and used successfully in removing contaminants ${ }^{35}$. Modification in the surface of silica gel has been explored in the last two decades for adsorption purposes. It is used successfully in the removal of both organic and inorganic pollutants. Silica gel is having a high adsorption capacity towards heavy metals and other contaminants. Despite having good adsorption capacity and easy regeneration, the major limitation of silica gel is its hydrophilic characteristics on its surface. Study shows that pore size of silica gel can be reduced by adding aluminum ions as silica growth inhibitor ${ }^{36}$. Reduction in pore size improves its adsorption capacity. 


\section{Non-conventional Adsorbents}

Non-conventional adsorbents include natural materials and bio-sorbents.

\section{Natural materials}

Clay and zeolites are included in natural materials. Their adsorption properties have been explained here.

\section{Clay minerals}

The chemistry of soil has a substantial effect on the performance of clay minerals as an adsorbent. The revolutionary work by many soil chemists regarding the role of clay minerals as an adsorbent was done efficiently ${ }^{37}$. The chemical properties of clay mainly affect the sorption behavior of soil. As per literature, most clay minerals work very efficiently in removing different types of contaminants from different kinds of waters ${ }^{38}$. Clay minerals are mainly made up of alumina and silica sheets. The presence of exchangeable ions and the ability of ions make the surface of clay highly porous. Some soil scientists have suggested that clay in both natural and modified forms is efficient enough to remove salts from water. Most clay particles adsorb metal ions very efficiently by the charge neutralization method because they are negatively charged ${ }^{39}$. As per literature, $\mathrm{pH}$ and temperature are two significant factors responsible for removing heavy metals from water by clay as an adsorbent ${ }^{40}$. Among all types of clay, montmorillonite has the highest sorption capacity compared to other clay minerals ${ }^{41}$. It is proven to be economical and potential adsorbent for the removal of heavy metals. Furthermore, clay can also be modified to increase its efficiency for the removal of dissolved contaminants. Kaolinite can be used efficiently to remove heavy metals, especially cadmium and lead ${ }^{42}$. Kaolinite can be used in both natural and modified forms. The adsorption behavior of some of the clay minerals has been tabulated in Table 3.

Table 3: Adsorption behaviour of different clay minerals for different adsorbates

\begin{tabular}{lccc}
\hline Adsorbents & Adsorbates & Optimum pH & References \\
\hline Montmorillonite & Heavy metals & 5 & 43 \\
Iron pillared Montmorillonite & Metal ion & 7.3 & 44 \\
Clay soil with Illite & Heavy metals & 8 & 45 \\
Montmorillonite \& Kaolinite & Metals \& Dyes & $\mathrm{NA}$ & 46 \\
Clay Minerals & Metals \& Dyes & 7 & 47 \\
Humic acid with Ca-montmorillonite & Metals ion & $\mathrm{NA}$ & 48 \\
\hline
\end{tabular}

\section{Zeolites}

Natural zeolite is used as low-cost adsorbents for dye and heavy metal removal from water and wastewater ${ }^{49}$. The natural zeolite has zeolitic mineral clinoptilolite with a small amount of mica, mordenite, quartz, and smectite. The effectiveness of zeolite in eliminating contaminants depends upon physical and chemical properties ${ }^{50}$. Zeolite is having a porous structure, which makes it efficient for the adsorption of dissolved impurities. Several studies show the excellent performance of zeolite to remove dissolved impurities from different kinds of water ${ }^{51}$. Adsorption of metal ions on zeolite undergoes the process of charge neutralization as zeolite is generally negatively charged. Zeolite can also be modified by organic surfactants, inorganic salts and leads to positively charged oxi-hydroxides, which help zeolite remove negatively charged contaminants by forming complexes ${ }^{52}$. Zeolite is one of the most prevalent and economical adsorbents to use for the removal of contaminants. Zeolite has excellent power to adsorb different cations at room temperature ${ }^{53}$. The efficiency of removal depends upon $\mathrm{pH}$, temperature, ionic strength of the solution, and initial concentration of contaminants in raw water ${ }^{54}$. Zeolite has advantages over other adsorbents because it is used in low concentrations with maximum efficiency ${ }^{55}$. With their natural advantages, zeolites have been used with great success. However, results depend on the type of raw water, its composition, and the zeolite dosage to be applied.

Zeolites have also been exploited to remove ammonia, present in high quantities in different surface water ${ }^{56}$. Literature shows that zeolite removes ammonia from surface water very efficiently with no adverse effect on water $\mathrm{pH}^{56}$. Zeolite in its natural and modified form has been studied to remove $\mathrm{Cu}^{2+}$ and $\mathrm{Mn}^{2+}$ from groundwater. Natural zeolite could remove $61-100 \% \mathrm{Cu}^{2+}$ and $\mathrm{Mn}^{2+}$ from ground water ${ }^{57}$. However, modified zeolite could remove $22-90 \% \mathrm{Cu}^{2+}$ and $\mathrm{Mn}^{2+57}$. Zeolites in 
natural and synthetic forms are harmless to human beings, economic, environmentally friendly, and easy to operate ${ }^{58}$. So it is one of the most promising adsorbents. The percentage removal of pollutants with the help of different pore sizes of zeolite has been summarized in Table 4.

Table 4: Removal of Contaminants from Zeolite

\begin{tabular}{lccc}
\hline Particle size of zeolite & lons & \% removal & Reference \\
\hline Natural zeolite with 0.3-0.84 nm size & $\mathrm{NH}_{4}^{+}$ & 95 & 59 \\
Modified zeolite with 5nm size & $\mathrm{NH}_{4}{ }^{+}$ & 90 & 60 \\
Natural zeolite with 0.25-2.83 nm size & $\mathrm{NH}_{4}{ }^{+}$ & $95 \%$ & 61 \\
Natural zeolite with 0.15nm to 1.0nm size & $\mathrm{Cu}^{2+} \mathrm{Pb}^{2+}$ & 82 & 62 \\
Natural zeolite with 0.6 to 0.8 mm size & $\mathrm{Pb}_{2}{ }^{+}$ & 90 & 63 \\
Modified zeolite with sodium chloride having & $\mathrm{NH}_{4}{ }^{+}$ & $99-100$ & 64 \\
Particle size <63 $\mu \mathrm{m}$ & & & \\
\hline
\end{tabular}

The removal process of pollutants by zeolite is a diffusion process. The diffusion process in zeolite consists of four phases which is shown in Figure 4.

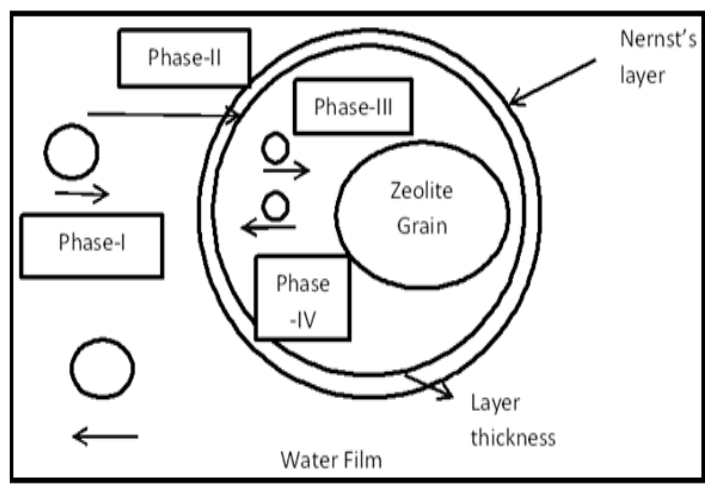

Fig. 4. Process of Zeolite ${ }^{65}$

\section{Bio-sorbents}

Bio-sorbents are one of the essential adsorbents used in industrial wastewater for the removal of dissolved impurities. A wide range of bio-sorbents is available such as industrial waste, agro waste, and chitosan derivatives. This section highlights the removal of contaminants using the bio-sorbents as adsorbents.

\section{Industrial waste}

A large number of solid waste materials are generated from different industries. Some of these wastes are used in landfills. Nowadays the industrial waste materials are used in large quantities for the eradication of various harmful pollutants. Over the past two decades, several industrial wastes have been explored to remove contaminants from water, considering the different advantages of these wastes, such as high availability, high adsorption tendency, and low cost ${ }^{66}$. Fly ash is one of these industrial waste materials produced in huge quantities from thermal power plants. Fly ash is also called pulverized fuel ash. Fly ash is generally used in making construction materials. The fly ash has a high concentration of alumina and silica, making them a promising adsorbent ${ }^{67}$. However, blast furnace slag, sludge, and red mud are also efficient adsorbents ${ }^{68}$. In the aluminium industry, red mud is considered the best adsorbent generated during alumina production ${ }^{69}$. However, red mud has its limitation. Red mud is poisonous because of its colloidal nature. Literature shows that fly ash is proven to be a low-cost and efficient adsorbent for dyes removal. It removed both acidic and basic dyes efficiently ${ }^{8}$. Organic pollutants like pesticides and phenolic groups are also removed very efficiently from wastewater by fly $a \mathrm{sh}^{70}$. Fly ash is also successfully used for the elimination of heavy metals. At high $\mathrm{pH}$ levels and low temperature, removal of $\mathrm{Pb}^{2+}, \mathrm{Cu}^{2+}, \mathrm{Zn}^{2+}$ was found to be more efficient with the help of fly ash. Among all three heavy metals, the highest removal was observed in $\mathrm{Zn}^{2+71}$. Study shows that fly ash is also used for antibiotic removal from pharma industry wastewater. Zhang et al., examined the ability of modified coal fly ash to remove the antibiotic ciprofloxacin from the wastewater $^{72}$. The study concluded that the usage of modified fly ash is far more beneficial than unaltered fly ash due to its enhanced properties and better adsorption characteristics.

Blast furnace slags have been used efficiently for few dyes, such as Basic blue 6, Acid yellow 376, and Basic violet $3^{53,66}$. However, it has not shown encouraging results for heavy metals removals. However, the role of sludge-based adsorbents is minimal. They are exploited for the removal of pharmaceuticals contaminants. However, it does not give encouraging results in the removal of dyes and heavy metals ${ }^{73}$. 


\section{Agro wastes}

Agriculture waste is mainly made up of cellulose, hemicellulose, and lignin. These materials are proven to be efficient adsorbents and are widely used to remove contaminants from wastewater. They have a wide application due to high carbon content, high availability, and low cost. As per literature, they have been widely used to remove pharmaceutical contaminants, heavy metals, and dyes ${ }^{74}$. Over the past two decades, few scientists applied agricultural waste to remove pharmaceutical pollutants ${ }^{75}$. Few antibiotics have been removed successfully by the use of agricultural waste ${ }^{1}$. Some agriculture wastes such as bamboo, wheat barn, and cocoa shell have been used successfully to prepare economically viable adsorbents to eliminate some anti-inflammatory drugs.

\section{Chitosan}

Chitosan is the most popular polymer used in water treatment. Chitosan is a water-insoluble polymer and is derived from chitin. It has medium molecular weight and consists of weakly charged glucose amine or $\mathrm{N}$-acetyl glucose amine derived from partial or full deacetylation of $\mathrm{N}$-acetyl glucose amine groups of chitin. The repeating units of chitosan are shown in Figure 5.

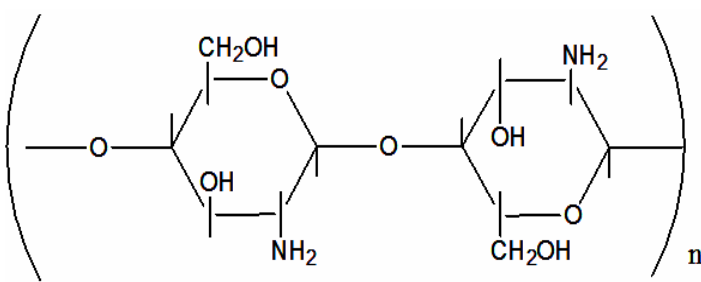

Fig. 5. Repeating unit of Chitosan

Chitosan has many diverse properties such as non-toxic, biodegradable, hydrophobicity, presence of hydroxyl, and amino groups. These properties make chitosan to be used more efficiently in water purification. Chitosan has been used successfully to remove both suspended and dissolved impurities ${ }^{76}$. A modified form of chitosan is used as an efficient adsorbent to remove pharmaceutical waste from industrial wastewater. Studies show that modified chitosan form is more efficient than commercially available chitosan ${ }^{77}$. Due to the presence of protonated amino groups, there is an electrostatic force of attraction between negatively charged pollutants and polymer chains. Due to the high affinity of chitosan with contaminants, in many studies, it has been used successfully for the removal of heavy metals, organic matter, and dyes. It is a promising material that can be modified in different manners such as cross-linking, grafting, and composite formation. The modified form of chitosan is used more successfully as adsorbents ${ }^{78}$. Many other bio-sorbents such as cashew nutshell, sawdust, orange peel, activated sludge, sawdust, cork powder, etc., have also successfully removed dissolved impurities from wastewater. The removal of different contaminants by bio-sorbents has been summarized in Table 5.

Table 5: Removal of contaminants from wastewater by bio-sorbents

\begin{tabular}{llc}
\hline Bio-sorbents & Types of Pollutants removed & Refe. \\
\hline Cashew nut shell & Metals & 79 \\
Saw dust & Methylene blue dye & 80,81 \\
Orange peel & Methylene blue dye & 82 \\
Activated Sludge & Pharmaceutical pollutants & 83,84 \\
Rubber seed coat & Phenolic pollutants & 85 \\
Saw dust & Heavy metals \& dyes & 1,86 \\
Cork powder & Pharmaceutical pollutants & 87 \\
Chitosan nanocomposites & Pharmaceutical pollutants & 88 \\
Sludge-based adsorbents & Metals \& Dyes & 89,90 \\
\hline
\end{tabular}

Generally, the adsorption capacity depends upon the chemical properties of adsorbents and texture. It is also essential to note that non-conventional adsorbents are very specific in their application and can be useful only for limited kinds of impurities. That is why using only a single type of adsorbent does not give encouraging results for complex types of wastewater. For example, clay mineral is not a very effective adsorbent for the removal of non-ionic contaminants. After thoroughly studying all kinds of conventional and non-conventional adsorbents, their advantages, characteristics, and disadvantages have been summarized in Table 6 .

\section{Future Prospects}

The adsorption technique is one of the best and most economical techniques used to remove soluble pollutants. Adsorbents are successfully used to remove pharmaceutical wastewater impurities, heavy metals, dyes, organic impurities, and many others. The review work discussed in this chapter describes different types of adsorbents and their usage for different kinds of wastewater. Therefore these references can be adopted for future development by technologists and environmentalists. Although the adsorption method is one of the most preferred techniques, it also has its limitation. Regeneration of adsorbents used for treatment is the greatest challenge. Among all adsorbents, activated carbon and zeolite are the most preferred ones. However, it is essential to understand the complex relationship between dissolved impurities of wastewater with different adsorbents so that the right choice of adsorbent can be made for the removal technique. 


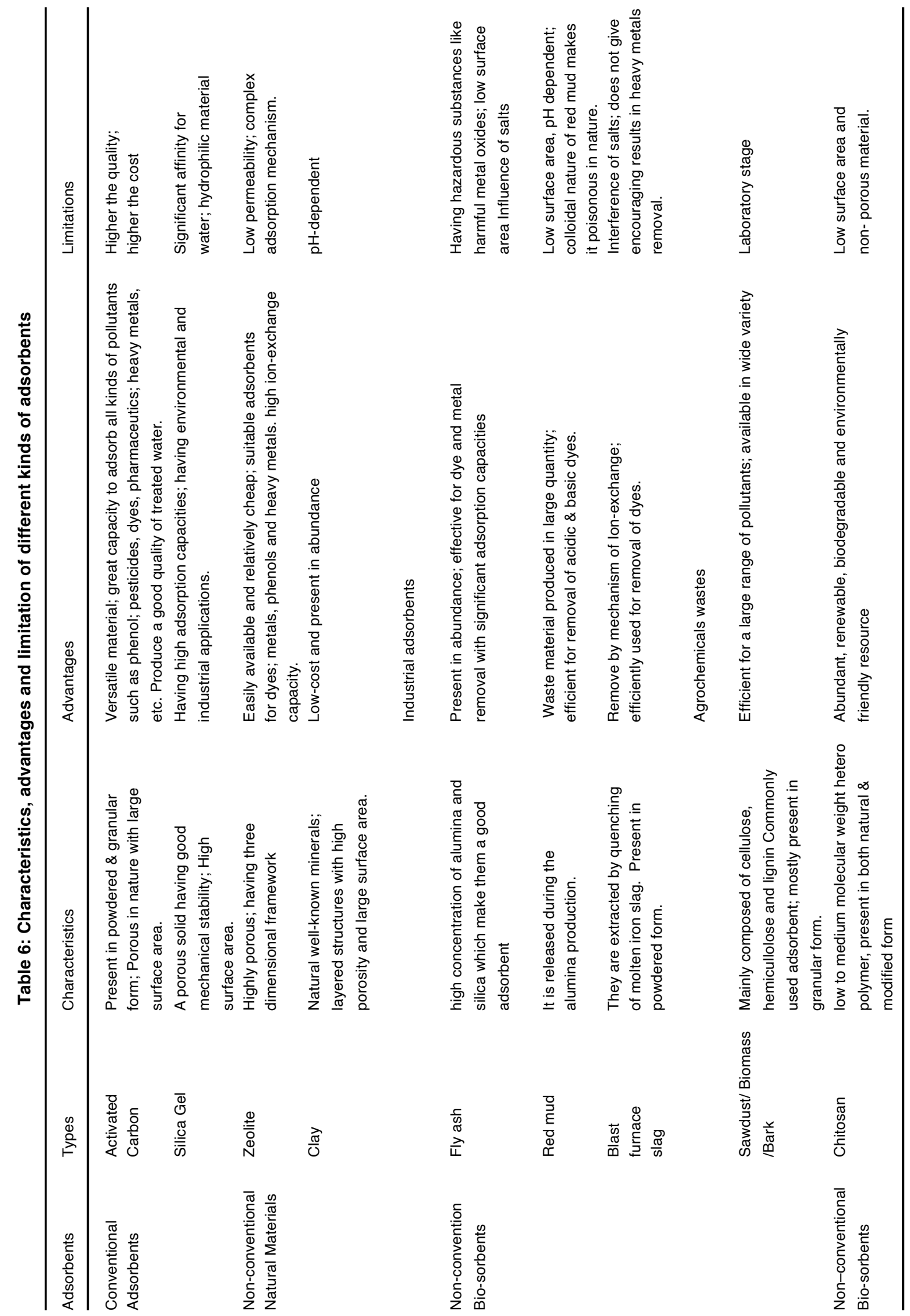


Furthermore, the adsorption method can be combined with the biological method for better results. Various adsorbents like almond seeds and starch can also be exploited for the removal of impurities. Keeping in view the applicability of the technique used here, it is expected that it can be helpful for different variety of water from a different origin.

\section{CONCLUSION}

Current studies in the field of adsorption were done to find a long-term solution for removing dissolved pollutants from different types of water. The technology for removing dissolved pollutants so far has a significant degree of variation in terms of their respective removal proficiencies. Variation in different kinds of contaminants in various types of water makes it difficult to handle. The fine fraction of dissolved matter carries a significantly high pollutants load compared to suspended matter. However, it is not possible to find out universal treatment technology to remove all types of dissolved matter from surface water, groundwater, and different industrial effluents.

So it is essential to embrace multidisciplinary techniques in which environmentalists, chemists, biologists, engineers can work together. It has been noted that various kinds of adsorbents have been used successfully for treating water having different impurities. Conventional adsorbents have been used more extensively due to their wide application. Activated carbon and silica gel are used not only for adsorbing impurities from domestic water but also for eliminating contaminants from industrial effluents. On the other hand, non-conventional materials have not yet been commercialized completely. However, non-conventional materials have also been used successfully to remove contaminants from a different source of water. Zeolite is having wide application in the removal of heavy metals in its modified form.

It has also been concluded that clay and zeolite have high sorption capacity and are very effective in removing dyes and pharmaceutical waste from wastewater.

Chitosan, agro waste, and industrial waste can be used significantly to remove dissolved matter from a different source of water because they are present in abundance and economically viable. Fly ash has been used more successfully in the removal of pesticides and phenolic groups.

\section{ACKNOWLEDGEMENT}

The authors would like to acknowledge the researchers on this subject. This paper is an attempt to consolidate the findings by all of them.

\section{REFERENCES}

1. Lather, H. A.; Global Nest. J., 2014, 16, 707-718.

2. Carolin, C. F.; Kumar, P. S.; Saravanan, A.; Joshiba, G. J.; Naushad, M. J. Environ. Chem. Eng., 2017, 5, 2782-2799.

3. Jabin, S.; Kapoor, J.K. Sustainable Green Chemical Process and their AlliedApplications, Springer Nature Switzerland. 2020, 289-309. DOI:10.1007/978-3-030-42284-4_10.

4. Antunes, M.; Esteves, V. I.;Guegan, R.; Crespo, J. S.; Fernandes, A. N.; Giovanela, M. Chem. Eng. J., 2012. 192, 114-121. https://doi.org/10.1016/j.cej.2012.03.062.

5. Munch, R.; Hwang, C. P.; Jackie. Water Sew. work., 1980, 127(12), 49-54.

6. Guo, H. ; You, F. ;Yu, S. ; Li, L.; Zhao, D. J. Membr. Sci., 2015, 496, 310-317. https://doi. org/10.1016/j.memsci.2015.09.005.

7. Liu, X. Q.; Hu, Q.; Fang, Z.; Xhang, X.; Zhang, B. Langmuir., 2009, 25, 3-8. https:// doi.org/10.1021/la802754t.
8. Wang, S.; Boyjoo, Y.; Choueib, A. ; Zhu, Z. H.; Water Res., 2005, 39, 129-138DOI: 10.1016/j.watres.2004.09.011.

9. Ding, R.; Zhang, P.; Seredych, M.;TBandosz, T. J. Water Res., 2012, 46, 4081-4090.

10. Kapoor, J. K.; Jabin, S.; Bhatia, H. S.; Kapoor, N. J. Ind. Res. Technol., 2011, 1, 114-118.

11. Azais, A.; Mendret, J.; Gassara, S.; Petit, E.; Deratani, A.; Brosillon, S. Sep. Purif. Technol., 2014, 133, 313-327. DOI: 10.1016/j. seppur.2014.07.007.

12. Abdel-Aziz, M. H.; Nirdosh, I.; Sedahmed, G. H. Industrial \& Engineering Chemistry Research (acs.org)., 2013, 52, 11655-11662. https://doi.org/10.1021/ie400548w.

13. Kapoor, J. K.; Jabin, S.; Bhatia, H. S. J. Chemistry \& Chem. Sci., 2011, 1(4), 267-275.

14. Radjenovic, J.; Petrovic, M.; Venturac, F.; Barcelo, D. Water Res., 2008, 42, 3601-3610 DOI: 10.1016/j.watres.2008.05.020. 
15. Crittenden, J. C.; Trussel, R. R.; Howe, K. J.; Tchobanoglous, G. Principles and Design. Second. ed. John Wiley \& Sons, New Jersey., 2005, 643-779.

16. Ganguly, M.; Parisa, A. A. ACS Omega., 2019, 4(7),12107-12120.DOI:10.1021/ acsomega. 9b00757.

17. Sharma, P.; Singh, A. K. ; Shahi, V. K. ACS Sustain. Chem. Eng., 2019, 7(1),1427-1436. DOI: 10.1021/acssuschemeng.8b05138.

18. Zolezzi, C.; Ihle, C. F.; Angulo, C.; Palma, P.; Palza, H. Ind. Eng. Chem. Res., 2018, 57(46),1572215730. DOI:10.1021/acs.iecr. 8b03879.

19. Kurniawan, T.A.; Chan, G. Y. S.; Lo, W. H.; Babel, S. Chem. Eng. J., 2006, 118, 83-98. https://doi.org/10.1016/j.cej.2006.01.015.

20. Crini, G. Prog. Polym. Sci., 2005, 30, 38-70. https://doi.org/10.1016/j.progpolymsci.2004. 11.002 .

21. Davis, T.A. ; Volesky, B.; Mucci, A. Water Res., 2003, 37, 4311-4330 https://doi.org/10.1016/ S0043-1354(03)00293-8.

22. Nageeb, M. Org. Pollut-Monit Risk Treat. Published online., 2013. doi:10.5772/54048

23. Li, Y.; Chen, W.; Hao, W.; Li, Y.; Chen, L. ACS Appl. Nano Mater., 2018, 1(9), 4756-4761. DOI: 10.1021 /acsanm.8b00983.

24. Renitha, A. A.; Kumar, S.; Srinivas, S.; Pridarshani, S.; Karthika, M. Water Treat., 2018, 87, 160-178.doi:10.5004/dwt.2017. 21311

25. Choy, K. K. H.; McKay, G.; Porter, J. F. Resour. Conserv. Recycl., 1999, 27, 57-71. https:// doi.org/10.1016/S0921-3449(98)00085-8.

26. Utrilla, J. R.; Prados, G.; Sanchez-Polo, M.; Ferro-Garcia, M. A.; Toledo, I. B. J. Hazard. Mater., 2009, 170, 298-305. DOI: 10.1016/j. jhazmat., 2009, 04, 096.

27. Llado, J.; Sole-Sardans, M.; Lao-Luque, C.; Fuente, E.; Ruiz, B. Proc. Safety Environ. Protect., 2016, 104, 294-303.

28. Basar, C. A.; Onal, Y.; Kilicer, T.; Eren, D. J. Hazard. Mater., 2005, 127, 73-80.doi: 10.1016/j.jhazmat.2005.06.025.

29. Lillo-Rdenas, M. A.; Cazorla, D. A.; Linares, A. Carbon., 2005, 43, 1758-1767.

30. Yangui, R.B.E., Removal of water pollution by adsorption on activated carbon prepared from olive waste cake and by biological treatment using linginolytic fungi. $\mathrm{PhD}$ thesis, 2013,Department of Chemical Engineering, National School of Engineers of Sfax, University Autonoma de Barcelona/University of Sfax.

31. Yahya, A. S.; Barghouthi, M. I.; El-Sheikh, A. H.; Walker, G. M. Dyes Pigments., 2008 77, 16-23. Doi:10.1016/j.dyepig.2007.03.001.

32. Phan, T. N. T.; Bacquet, M.; Morcellet, M. J. Incl. Phenom. Macrocycl. Chem., 2000, 38, 345-359.

33. Yang, T. R. Adsorbents: fundamentals and applications. Wiley-Inter Science, Hoboken., 2003, 424.

34. Martucci, A.; Cremonini, M. A.; Blasioli, S.; Gigli, L.; Gatti, G.; Marchese, L.; Braschi, I. Micropor. Mesopor. Mat., 2013, 170, 274-286 https://doi. org/10.1016/j.micromeso. 2012.11.031.

35. Van Der Voort, P.; Esquivel, D.; De Canck, E.; Goethals, F.; Van, Driessche, I.; RomeroSalguero, F. J. Chem. Soc. Rev., 2013, 42, 39133955. https://doi.org/10.1039/C2CS35222B.

36. Ying, J. Y.; Mehnert, C. P.; Wong, M. S. Angew. Chem. Int., 1999, 38, 56-77. doi: 10.1002/(SICl)1521-3773(19990115)38:1/2.

37. Hwang, S. I.; Lee, K. P.; Lee, D. S. Soil Sci. Soc. Am. J., 2002, 66, 1143-1150.

38. Jamenoz, C.; Tejedor, M.; Rodriguez, M. Eur. J. Soil., 2007, 58(2), 445-4497. https://doi. org/10.1111/j.1365-2389.2007.00897.x

39. Qi, F.; Zhang, R.; Yong, X. L.; Niu, N. H. Soil \& Tillage Res., 2018, 184, 45-51, https://doi. org/10.1016/j.still.2018.06.011.

40. Yang, S.; Sheng, G.; Tan, X.; Hu, J.; Du, J.; Montavon, G.; Wang, X., Geochim Cosmochim. Ac., 2011, 75, 6520-6534.

41. Akpomie, K. G.; Dawodu, F. A. J. Basic Applied Sci., 2016, 5(1),1-12https://doi. org/10.1016/j.bjbas.2016.01.003.

42. Al-Essa, K.; Khalili, F. Am. J. Appl. Chem., 2018, 6(1), 25-34. https://doi.org/10.11648/j. ajac.20180601.14.

43. Warkentin, B. O.; Arbaoui, F. Chem. Eng. J., 2011, 172(1), 230-236. DOI: 10.1016/j. cej.2011.05.095.

44. Ararem, A.; Bouras, O.; Arbaoui, F. Chem. Eng. J., 2011, 172(1), 230-236.DOI: 10.1016/j. cej.2011.05.095. 
45. Giannakopoulou, F.; Haidouti, C.; Chronopoulou, A.; Gasparatos, D. J. Hazard. Mater., 2007, 149, 553-556. doi:10.1016/j.jhazmat.2007.06.109.

46. Bhattacharyya, K.G.; Gupta, S. Adv. Colloid Int. Sci., 2008,140,114-131. https://doi. org/10. 1016/j.cis.2007.12.008.

47. Ngulube, T.; Gumbo, J.R.; Masindi, V.; Maity, A. J. Environ. Manag., 2017, 191, 35-57. https:// doi.org/10.1016/j.jenvman.2017.12.031 DOI: 10.1016/j.jenvman.2016.12.031.

48. Wu, P.; Zhang, Q.; Dai, Y.; Zhu, N.; Dang, Z.; Li, P.; Wu, J.; Wang, X.Geoderma., 2011, 164, 215-219.

49. Taffarel, S.R.; Rubio, J. Mineral. Eng., 2009, 22, 336-343. DOI:10.1016/j.mineng.2008. 09.007.

50. Sheta, A.S.; Falatah, A.M.; Al-Sewailem, M. S.; Khaled, E. M.; Sallam, A. S. H., Micropor. Mesopor. Mater., 2003, 61, 127-136.doi: 10.1016/S1387-1811(03)00360-3.

51. Li, Z.; Jean, J. S.; Jiang, W. T.; Chang, P. H.; Chen, C. J.; Liao, L. J. Hazard. Mater., 2011, 187, 318-323 DOI:10.1016/j.jhazmat. 2011.01.030.

52. Miladinović,N.; Weatherley, L. R. Chem. Eng. J., 2007, 135, 15-24 DOI:10.1016/j.cej. 2007.02.030.

53. Caputo, D.; Pepe, F. Micropor. Mesopor. Mater., 2007, 65, 222-231.

54. Sarioglu, M. Sep. Purific. Tech., 2005, 41, 1-11.

55. Doula, M. K.; Dimirkou, A. J. Hazard. Mater., 2008, 151, 738-745.

56. Rahmani, A. R.; Mahvi, A. H.; Mesdaghinia, A. R.; Nasseri, N., J. Environ. Sci. Tech., 2004, 1(2), 125-133.

57. Doula, M. K. WaterRes., 2009, 43(15), 36593672.

58. Wang, S.; Peng, Y. Chem. Eng. J., 2010, 156, 11-24. DOI: 10.1016/j.cej.2009.10.029.

59. Koon, J. H.; Kaufmann, W. J. J. Wat. Pollut. Contr. Fed., 1975, 47(3), 448-465.

60. Milan, Z.; Sénchez, E.; Weiland, P.; deLas, Pozas, C.; Borja, R.; Mayari, R.; Rovirosa, N. Chem. Eng. J., 1997, 66(1), 65-71. https://doi. org/10.1016/S1385-8947(96)03180-4.

61. Nguyen, M.L.; Tanner, C. C.New Zealand. J. Agri. Res., 1998, 41(3), 427-446https://doi.or g/10.1080/00288233.1998.9513328.

62. Park, J. B.; Lee, S. H.; Lee, J. W.; Lee, C. Y. J. Hazard. Mater., 2002, 95(1-2), 65-79 DOI: 10.1016/s0304-3894(02)00007-9.

63. Medvidović, N.; Perić, J.; Trgo, M. Sep. Sci. Technol., 2008, 43(4), 944-959https://doi. org/10.1080/01496390701870622.

64. Šiljeg, M.; Foglar, L.; Kukučka, M. J. Hazard. Mater., 2010, 178, 572-577DOI:10.1016/j. jhazmat.2010.01.123.

65. Margeta, K.; Logar, N. Z.; Siljeg, M.; Farkas, A. Wat. Treat., 2013, 5, 81-112. DOI: $10.5772 / 50738$.

66. Jain, A. K.; Gupta, V. K.; Jain, S. Environ. Sci. Technol., 2004, 38, 1195-1200.

67. Cho, H.; Oh, D.; Kim, K. A. J. Hazard. Mater., 2005, 127, 187-195. DOI: 10.1016/j. jhazmat.2005.07.019.

68. Wang, S.; Ang, H.M.; Tadé, M.O., Chemosphere., 2008, 72, 1621-1635. https:// doi.org/10. 1016/j.chemosphere.2008.05.013.

69. Xu, B.; Qi, F.; Zhang, J.; Li, H.; Sun, D.; Robert, D.; Chen, Z.Chem. Eng. J., 2016, 284, 942-952. DOI: 10.1016/j.cej.2015.09.032

70. Ahmaruzzaman, M. Adv Colloid Int Sci. 2008,143, 48-67.https://doi.org/10.1016/j. cis.2008.07.002.

71. Swami, D.; Buddhi, D. Int. J. Environ. Poll., 2006, 27, 324-346. https://doi.org/10.1504/ IJEP.2006.010576.

72. Zhang, C. L.; Qiao,G. L.; Zhao, F.; Wang, Y. J. Mol. Liq., 2011, 163, 53-56 DOI:10.1016/j. molliq.2011.07.005.

73. Urase, T.;Kikuta, T. WaterRes., 2005, 39,12891300. DOI:1-.1016/j.watres.2005.01.015.

74. Madurwar, M. V.; Ralegaonkar, R. V.; Mandavgane, S. A. Constr. Build Mater., 2013, 38, 872-878DOI:10.1016/j.conbuildmat. 2012.09.011.

75. Kadirvelu, K.; Kavipriya, M.; Karthika, R. C.; Vennilamani, N.; Pattabhi, S. Bioresour. Technol., 2003, 87, 129-132.

76. Kyzas, G. Z.; Bikiaris, D. N.; Seredych, M.; Bandosz, T. J.; Deliyanni, E. A. Bioresour. Technol., 2014, 152, 399-406 DOI: 10.1016/j. biortech.2013.11.046.

77. Falk, B.; Garramone, S.; Shivkumar, S. Mater. Lett., 2004, 58, 3261-3265. DOI: 10.1016/j. matlet.2004.05.072. 
78. Kumar,M. N. V. R. React. Funct. Polym., 2000, 46, 1-27. https://doi.org/10.1016/ S1381-5148(00)00038-9.

79. Kumar, P.S.; Ramalingam, S.; Sathyaselvabala, V.; Kirupha, S. D.; Sivanesan, S. Desalination., 2011, 266, 63-71.

80. Suganya, P. S.; Kumar, A.; Saravanan, P. S.; Rajan, C.; Kumar, R. Environ. Toxicol. Phar., 2017, 50, 45-57. DOI: 10.1016/..etap.2017.01.014.

81. Gupta, T.; Lataye, D. Indian Journal of Chemical Technology., 2019, 26, 52-68.

82. Kumar, P. S.; Fernando, P. S. A.; Ahmed, R. T.; Srinath, R.; Priyadharshini, M.; Vignesh, M. A.; Thanjiappan, A. Chem. Eng. Commun., 2014, 201,1526-1547. https://doi.org/10.10 80/0986445.2013.819352.

83. Gobel, A.;Homsen, A.; Cardell,C. S. M.; Joss, A.; Giger ,W. Environ. Sci. Technol., 2005, 39, 3981-3989.

84. Taboada-Santos, A.; Rivadulla, E.; Paredes, L.; Carballa, M.; Romalde, J.; Lema, J.
M. Water Res., 2020, 169, 115258. doi: 10.1016/j.watres.2019.115258.

85. Rengaraj, S.; Moon, S. H.; Sivabalan, R.; Arabindoo, B.; Murugesan, V. J. Hazard. Mater., 2002, 89, 185-196 DOI:10.1016/s 0304-3894(01)00308-9.

86. Chikri, R.; Elhadiri, N.; Benchanaa, M.; El Maguana, Y. J. Chem., 2020, 1-17.

87. Villaescusa, I.; Fio, N.; Poch, J.; Bianchi, A.; Bazzicalupi, C. Desalination., 2011, 270, 135-142.

88. Kyzas, G. Z.; Bikiaris, D. N.; Seredych, M.; Bandosz, T. J.; Deliyanni, E. A. Bioresour. Technol., 2014, 152, 399-406 DOI: 10.1016/j. biortech.2013.11.046.

89. Devi, P.; Saroha, A.K. Sci. Total Environ., 2017, 578, 13-33. https://doi.org/10.1016/j. scitoten.2016.10. 220.

90. Raval, N.P.; Shah, P.U.; Shah, N.K. J. Environ. Manag., 2016, 179, 1-20. https:// doi.org/10.1016/j.jenvman.2016. 04.045. 